\title{
EI Plan Director de la Sede de Égara (Terrassa): un modelo de gestión del patrimonio monumental pictórico y arqueológico
}

\author{
Carles Sánchez Márquez ${ }^{a}$, Domènec Ferran ${ }^{b}$ \\ ${ }^{a}$ Museo de Terrassa, carrer Font Vella 28, 08221 Terrassa, carles.sanchezmarquez@terrassa.cat; ${ }^{b}$ Museo de Terrassan, carrer Font \\ Vella 28, 08221 Terrassa, domenec.ferran@terrassa.cat.
}

\section{Resumen}

La Sede de Égara es un conjunto monumental constituido por tres iglesias (Santa María, San Pedro y San Miguel) que formaron parte de un importante recinto episcopal cristiano -el obispado de Égara-de época visigoda (siglos V-VIII). Entre los años 1994 y 2010 el Ayuntamiento de Terrassa, en convenio con la parroquia de San Pedro y el obispado de Barcelona, impulsó el Plan Director de las Iglesias de San Pedro de Terrassa, un proyecto que contó con la colaboración del Gobierno de España, la Generalitat de Catalunya y la Diputación de Barcelona. El presente artículo tiene por objeto mostrar el modelo de gestión contemplado en el Plan Director, que ha permitido estudiar, preservar y potenciar la arquitectura del conjunto y las pinturas murales de época visigoda de los ábsides de Santa María, San Miguel y el retablo mural de San Pedro.

Palabras clave: Sede de Égara, Terrassa, Plan Director, Santa María, San Pedro, San Miguel, pinturas.

\section{Abstract}

The Episcopal See of Egara is a Christian set composed of three churches (Saint Mary, Saint Peter and Saint Michael, which was built in the Visigothic period. The Director's Plan of the See of Egara was promoted by Terrassa City Council between 1994 and 2010 under an agreement with the parish Church of St. Peter and the Bishopric of Barcelona, and thanks to the collaboration of the Spanish and Catalan Governments. The main goal of this paper is to show the management model that has been developed during the Director's Plan. This has enabled us to study, preserve and promote the architecture of the set and especially the wall paintings from Visigothic period that adorn the apses of the three churches.

Keywords: See of Egara, Terrassa, Director's Plan, Saint Mary, Saint Peter, Saint Michael, paintings. 


\section{Introducción}

La Sede de Égara (Terrassa) es un conjunto monumental único en Europa que presenta una trayectoria de continuidad en la historia (Ainaid de Lasarte, 1976; Ferran,2009). La designación del antiguo municipium flavium de Égara como sede episcopal (c.450) (Martí i Bonet, 1992) supuso la edificación de un gran complejo cristiano formado por la residencia episcopal, la catedral de tres naves de Santa María y el baptisterio a sus pies, el edificio funerario de San Miguel y la parroquia de San Pedro (Figs. 1,2). La pervivencia de elementos arquitectónicos y artísticos tanto del período del obispado (siglos V-VIII), como de las transformaciones llevadas a cabo en la etapa románica (siglo XII), convierten este conjunto en un momento singular del patrimonio europeo (García, Moro, Tuset, 2009).

\section{EI Plan Director de la Sede de Égara}

Entre los años 1994 y 2010 el Ayuntamiento de Terrassa impulsó el "Proyecto para el desarrollo cultural e integración urbana del conjunto monumental de las Iglesias de San Pedro", para el cual contó con la colaboración de la Generalitat de Catalunya, el Arzobispado de Barcelona y la Diputación de Barcelona (AAVV, 1994). El objetivo principal era llevar a cabo diversas actuaciones de restauración, arqueológicas, museísticas, arquitectónicas y de dinamización cultural, para visibilizar la Sede de Égara y afianzar el vínculo entre el monumento, su entorno y la ciudadanía.

En el marco del Proyecto se desarrollaron dos subproyectos: el "Plan especial del conjunto monumental y su entorno" y el "Plan Director del conjunto monumental de les Iglesias de San Pedro", siendo este último el objeto de este artículo (AAVV, 1998 y 2011). En el marco de actuación del Plan Director se llevaron a cabo diversas acciones para profundizar en el conocimiento científico del conjunto de las tres iglesias y difundirlo entre los ciudadanos: adecuación y restauración del conjunto, definición de los usos litúrgicos y culturales, intervenciones arqueológicas y museografía.

Para la redacción y ejecución del Plan Director se firmó un convenio de colaboración entre la Generalidad de Cataluña, la Diputación de Barcelona, el Ayuntamiento de Terrassa, el obispado de Barcelona y la parroquia de San Pedro. También participaron en la ejecución del mismo la Caja de Terrassa, el Ministerio de Cultura y el Ministerio de Fomento. La aportación económica fue: Generalitat de Catalunya (4.157.958 euros); Diputación de Barcelona (2.859.958 euros); Gobierno de España, Fomento y Cultura (2.419.405 euros); Caja de Ahorros de Terrassa (1.803.040 euros); Ayuntamiento de Terrassa (1.382.818 euros).

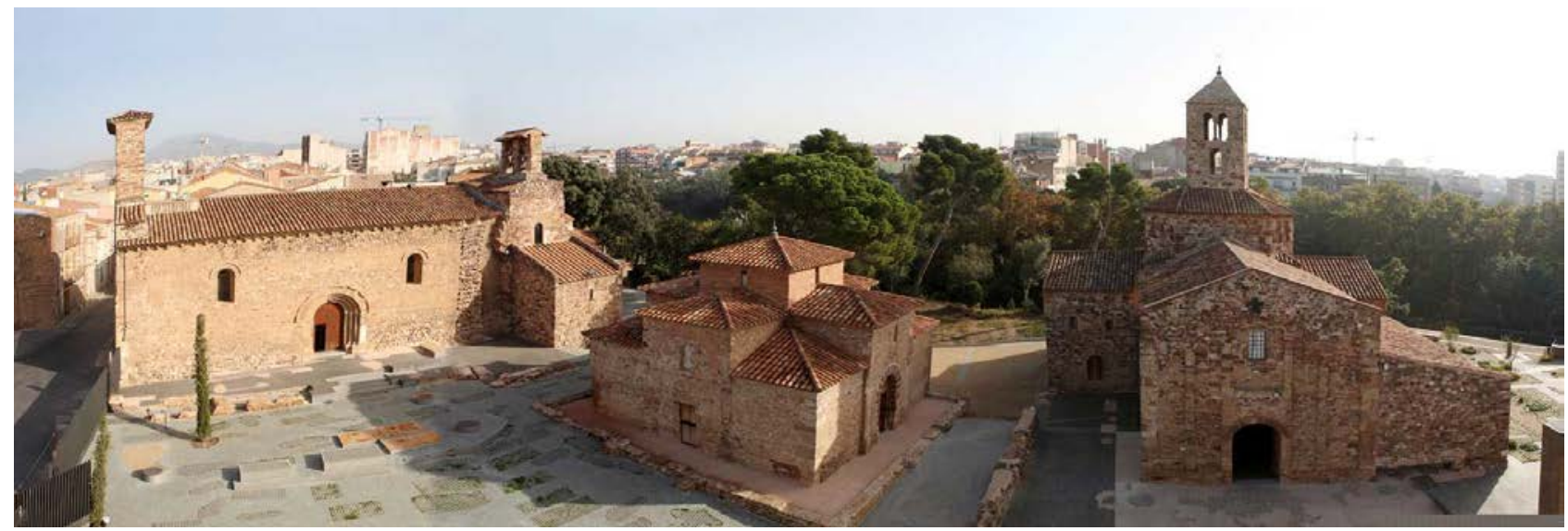

Fig. 1 Vista general del complejo episcopal de Égara en la actualidad. Fotografía. Badia/Casanova, MdT 


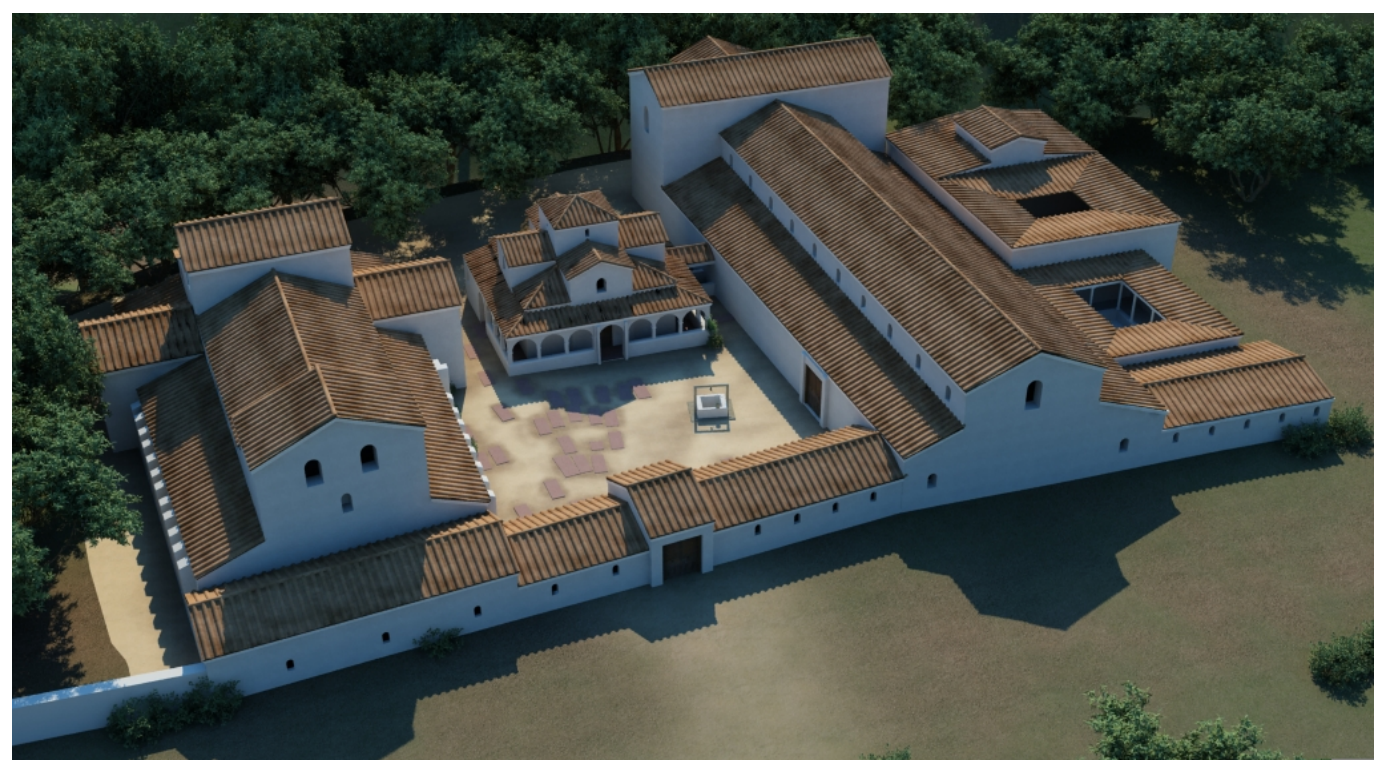

Fig. 2 Reconstrucción virtual del conjunto episcopal de Égara. Dualmultimèdia. Según M. G. Garcia, A. Moro y F. Tuset

El Plan Director fue redactado en el año 1998 por el equipo técnico del Servicio de Patrimonio Arquitectónico de la Generalitat de Catalunya -formado por Antoni Navarro, Alfred Pastor, Eduard Riu y Albert Sierra-, el director del Museo de Terrassa (Domènec Ferran) y el arquitecto Pere Riera, de RGA Arquitectes. Este extenso documento establece las directrices de las actuaciones en el monumento, que tenían por objeto la presentación, interpretación y comunicación más adecuada de la Sede de Égara desde el punto de vista patrimonial y cultural.

Derivados del Plan, se redactaron los diversos proyectos ejecutivos, en paralelo al inicio de los primeros estudios arqueológicos, históricos, documentales, antropológicos, de conservación y restauración de bienes muebles e inmuebles, condiciones ambientales y estructurales y museológicas. Entre otros, conviene subrayar el proyecto museológico del recinto monumental; el de la pasarela que comunica la Sede de Égara con el sector este de la ciudad; el proyecto de los edificios de San Pedro, San Miguel y Santa María; el proyecto de los nuevos Servicios Parroquiales, del Recinto monumental y el de la Rectoría.

\section{1. Ámbito del patrimonio: arqueología, museografía y conservación}

El año 1995 marca el inicio de las campañas arqueológicas, dirigidas por el arqueólogo Antoni Rigo y con la coordinación de Francesc Tuset. La siguiente campaña, dirigida por el arqueólogo terrasense Antonio Moro, se llevó a cabo en los años 1996-1997. Esta intervención, focalizada en el espacio entre las cabeceras de Santa María y San Miguel, puso al descubierto los primeros restos de presencia cristiana en el recinto, concretamente tumbas de tégula y cámaras funerarias fechadas de la segunda mitad el siglo IV. Tras estas primeras acciones, des del año 1999 y hasta 2003 se llevaron a cabo campañas de excavación casi ininterrumpidas. Este proceso de investigación, el más largo y extenso de la historia del yacimiento, ha permitido conocer a fondo la evolución cronológica del espacio desde los primeros pobladores ibéricos hasta la actualidad.

El Plan Director también contemplaba una propuesta específica de consolidación, restauración y protección del monumento. Así, entre los años 2001 y 2003 se desarrolló el primer proyecto de restauración arquitectónica de las cubiertas y la sacristía de San Pedro, que evidenció la existencia de aberturas y elementos de la primera iglesia parroquial de tres naves, del siglo VI. Paralelamente, entre los años 2002-2003 se construyó, previa excavación arqueológica, el nuevo edificio de Servicios Parroquiales. En el 2003 també se ejecutó el proyecto de una de las piezas más singulares de la de nueva construcción, la pasarela colgante sobre el Parque de Vallparadís, que comunicaba el recinto eclesiástico con el sector oriental de la ciudad.

La restauración de la iglesia de San Miguel se efectuó en el año 2005. En este sentido, una de las actuaciones más visibles fue la reapertura de los tres accesos del edificio, siendo las puertas norte y oeste totalmente originales. También 
fueron restauradas las pinturas murales que decoran el ábside, una actuación que permitió reconocer nuevos elementos de la composición pictórica (Fig. 3).

Fig. 3 San Miguel de Terrassa. Detalle de las pinturas con los apóstoles arrodillados

Por último, la iglesia de Santa María fue restaurada en los años 2007-2008. En el marco de esta intervención fueron recuperados elementos de la construcción románica, las estructuras pre-episcopales del subsuelo, y se restauraron las pinturas de la cuenca absidal (datadas en el siglo VI), una acción que puso al descubierto una decoración completa desde un zócalo rojizo hasta el espacio cenital con varias figuras y motivos ornamentales (Fig.4).



Fig. 4 Interior de la iglesia de Santa María

El proyecto de adecuación del recinto culminó en el año 2008 con la instalación de una nueva pavimentación que permite visualizar, en un plano contemporáneo mediante adoquines con códigos y colores, las diferentes etapas históricas del conjunto monumental (Figs. 5 y 6). Asimismo, el nuevo pavimento facilita el reconocimiento de las diversas estructuras arqueológicas que se encuentran debidamente protegidas, desde el periodo ibero-romano hasta la etapa moderna, destacando el período del obispado de Égara. Donde fue posible, se conservaron los muros originales con una capa de protección en el nivel superior. En este sentido, es preciso destacar la museización e iluminación de las tumbas de la necrópolis episcopal. Todos los enterramientos presentan una pequeña iluminación puntual que evoca la lámpara del alma de cada una de las tumbas, y se complementa con unas luces rasantes y unos báculos. 
También forma parte de esta actuación la nueva valla perimetral del conjunto, que sigue los parámetros de las estructuras metálicas verticales que conforman la barandilla de la pasarela de Vallparadís, sistema que permite una visión transparente frontal pero al mismo tiempo mantiene una cierta opacidad en la visión desde fuera del monumento.

Las obras de reforma de la rectoría fueron realizadas en el año 2009. Este proyecto consolidó gran parte de la edificación y dotó al Conjunto Monumental de nuevos espacios museísticos. A inicio de la calle de la Rectoría se habilitó una nueva entrada cultural, con espacios de acogida y dos niveles. En la planta baja se conservan la mayor parte de restos arqueológicos de la etapa de la sede episcopal, con las tres naves de la catedral, el baptisterio en la nave central y espacios funerarios en la nave norte. La visita a la planta baja se realiza por unas pasarelas con pavimento de vidrio, y en el espacio del baptisterio se proyecta una recreación virtual del conjunto catedralicio.

La primera planta es ocupada por la vivienda rectoral, de uso privado, que no forma parte de la visita. Finalmente, la segunda planta está dividida en dos bloques funcionales, el de nueva construcción, que constituye un espacio de acogida de visitantes, y la parte de la antigua rectoría, que conserva la sala principal con decoración barroca en el techo y custodia el retablo gótico de San Pedro. Existen dos espacios anexos, el que está situado al oeste funciona como mirador sobre el baptisterio y acoge la proyección de un audiovisual sobre la historia y las intervenciones más recientes del conjunto monumental. Por otra parte, la terraza-mirador de la cubierta del edificio permite contemplar el monumento y al mismo tiempo constituye el punto de partida para la visita, que se realiza con un sistema de paneles explicativos y audioguía.

En el año 2010 se procedió a la restauración del retablo mural del ábside de San Pedro, dirigida por el Instituto de Conservación y Restauración de Bienes Culturales del Ministerio de Cultura. La última de las intervenciones en el conjunto corresponde a la restauración de la nave y cubierta románicas del edificio parroquial de San Pedro, realizada entre los años 2013 y 2014.


Figs. 5 y 6 Restos arqueológicos de la cabecera de la basílica pre-episcopal (c.385-s.IV). Antes y después de la museización

\section{2. Ámbito socio-cultural. La Sede de Égara: epicentro de la cultura}

El Plan Director también tuvo en consideración la utilización de los valores estratégicos del monumento y de la zona donde se ubica para convertirlo en un icono cultural y en un elemento identitario de la ciudad. En relación a esta idea, desde la finalización del Plan Director hasta la actualidad se han desarrollado toda una serie de acciones con el objetivo de garantizar el uso social del monumento: elaboración de un calendario de actividades estable dentro de la programación cultural de la ciudad (conciertos de música clásica, música moderna, teatro, poesía, exposiciones); actividades didácticas relacionadas que permiten dar a conocer el monumento a todos los públicos (visitas, itinerarios, talleres, actividades teatralizadas, actividades en lengua extranjera); jornadas de puertas abiertas en fechas señaladas (Picnic Jazz, Feria Modernista, Día Internacional de los Museos, Fiesta Mayor de Terrassa y Jornadas Europeas de Patrimonio en Cataluña); celebración de jornadas festivas organizadas por entidades culturales de la ciudad (Minyons de Terrassa: Día del Patrimonio en la Seu d'Ėgara; Centre d'Arts Escèniques de Terrassa; Festival poético "Elixir"; Orquestra de Cambra Terrassa 48). 


\section{El proyecto de candidatura a Patrimonio Mundial de la UNESCO}

Las diversas intervenciones arqueológicas, artísticas y de restauración realizadas en el marco del Plan Director, pusieron al descubierto toda una serie de singularidades en el conjunto episcopal de Égara, que llevaron a plantear la posibilidad de que el monumento iniciase el camino para ser declarada Patrimonio Mundial de la UNESCO. El proyecto comenzó su andadura administrativa en el año 2015, y alcanzó una meta importante el mes de febrero del 2019 cuando fue incorporado a la Lista Indicativa de Patrimonio Mundial de la UNESCO (https://whc.unesco.org/en/tentativelists/6378/). Debido a su excepcionalidad en el marco del patrimonio cultural europeo, en este momento el Ayuntamiento de Terrassa sigue trabajando en el proyecto de candidatura para obtener la distinción de Patrimonio de la Humanidad, a partir de la convicción, basada en argumentos científicos, de su valor universal excepcional.

\subsection{Un eslabón perdido en los contactos entre el Occidente y el Oriente mediterráneo}

Sin duda, el elemento que confiere una mayor singularidad al conjunto de Terrassa es la decoración pictórica de los ábsides de Santa María, San Miguel y San Pedro. Ésta ha sido objeto de un amplio debate científico focalizado en resolver dos interrogantes: la iconografía y su datación. Josep Puig i Cadafalch fue el primero en llevar a cabo un análisis minucioso de las pinturas, en el que proclamaba la identidad estilística (y por lo tanto cronológica) entre las pinturas murales de Santa María y las de San Miguel (Puig i Cadafalch, 1931,1932 y 1948). El autor relacionó el estilo y la iconografía de las pinturas con Siria y con los mosaicos de Ravenna, lo que le llevó a situar el conjunto pictórico en el siglo VI. En contraposición a la hipótesis cronológica planteada por Puig i Cadafalch, apoyada por una parte de la historiografía de la época, para otros autores como Milagros Guardia y Carles Mancho, las pinturas fueron realizadas en época carolingia, cuando Égara había dejado de ser sede episcopal (Pijoan, 1948, p. 43: Guardia, 1992; Mancho, 2012 y 2018)

Sin embargo, los datos aportados por los últimis estudios llevado a cabo por el equipo de arqueólogos (García Llinares, Moro, Tuset, 2009), historiadores del arte (Ferran 2009 i 2015; Sánchez, 2019), restauradores (ARCOR, 2002; Vilaseca, Guasch, 2004) y epigrafistas (López, Gorostidi, 2015), sitúan la cronología de las pinturas de Santa María y San Miguel en el momento de edificación de los templos, es decir, en el siglo VI. Esta datación se fundamenta básicamente en tres evidencias: técnica, paleográfica e iconográfica. Por un lado, la diagnosis de materiales ha revelado una contemporaneidad entre los morteros de las juntas del ábside y del intonaco, sobre el que se aplican las pinturas. Ello nos lleva a pensar que la pintura es contemporánea a la construcción de la cúpula. Por el otro, en el año 2015 un equipo de epigrafistas analizó las inscripciones conservadas en las pinturas de San Miguel y determinó que se trataba de formas propias de la epigrafía paleocristiana de época visigoda (Gorostidi, Vilar, 2015).

Finalmente, por lo que se refiere a la iconografía de los ciclos pictóricos, en Terrassa encontramos la presencia de unos temas iconográficos muy vinculados a los repertorios propios del siglo VI en el Mediterráneo Oriental, en el arte Bizantino y el arte copto. En este sentido, la composición de la cúpula de Santa María, la teofanía sinóptica de San Miguel con el colegio apostólico y la inscripción Cristo "Emmanuel", así como otros elementos como las plumas de pavo real, nos remiten a la iconografía de la pintura del siglo VI, que habría llegado a Terrassa mediante el contacto directo con el mundo bizantino. Los vínculos con el arte del Oriente mediterráneo también son palpables en el campo de la arquitectura. En este sentido, innovaciones arquitectónicas como el realzamiento de la cúpula de San Miguel (que nos remite directamente a modelos de la arquitectura bizantina), permiten catalogar el conjunto de Égara como una pieza clave para entender este contexto de transferencia cultural que se produjo entre el Occidente y el Oriente mediterráneo durante los siglos V-VII. En este sentido, no podemos olvidar que en esta época la costa mediterránea de Hispania conjugaba la presencia hispanorromana con los visigodos (establecidos en el Reino Visigodo de Toledo), y los bizantinos (muy bien establecidos en el sur de la península ibérica y Baleares desde el año 552). En este contexto, se produjeron numerosos contactos e influencias con el norte de África, la península itálica, y sobre todo el Oriente mediterráneo (Siria y el Egipto copto).

¿Cuál fue la vía de recepción de estos temas orientales en Terrassa? Sabemos que los visigodos se sintieron especialmente fascinados por la opulencia y la riqueza de Bizancio, y favorecieron la entrada de la moda bizantina a la península ibérica. En el caso de la Sede de Égara, los viajes de eclesiásticos o la llegada de artistas griegos a la provincia eclesiástica de la tarraconense pudieron ser la vía de recepción de determinados motivos iconográficos y soluciones arquitectónicas vinculadas al Mediterráneo oriental. Todo ello convierte la arquitectura de la Sede episcopal de Égara y sus pinturas en una evidencia palpable de esta herencia de contactos que se produjeron en el siglo VI en el 
arco mediterráneo. Un ejemplo singular de una cultura particular, la cultura cristiana del siglo VI, de la que desgraciadamente tan solo han sobrevivido algunas Biblias producidas en Oriente (Constantinopla, Siria, Palestina), así como conjuntos decorativos parciales en Egipto (Capilla de Apolo de El-Bawit, necrópolis de Al-Baqawat). A este respecto, conviene subrayar que Terrassa es el único conjunto entre las sedes episcopales antiguas (siglos V-VIII) conservadas en Occidente que mantiene vestigios de su decoración pictórica. Valencia, Barcelona, Mérida, Aosta (Italia), Ginebra (Suiza), Porec (Croacia) y Grenoble (Francia) conservan vestigios arquitectónicos, pero no pintura mural.

Por último, no podemos olvidar que, a pesar de la innegable influencia del arte de la civilización bizantina, Terrassa es un conjunto episcopal construido en época de dominación visigoda en la península ibérica. Si bien es cierto que han pervivido notables ejemplos de la arquitectura de época visigoda (San Pedro de la Nave, San Juan de Baños, Santa María de Quintanilla de las Viñas), es importante subrayar que no se conserva pintura mural de este período integrada en un complejo episcopal monumental, de manera que la Sede de Égara es también una manifestación única y excepcional del arte del pueblo hispanovisigodo.

Se trata, en definitiva, de un monumento clave para entender la transferencia de culturas que tuvo lugar entre los siglos V-VI: la población de cultura hispanorromana, el pueblo visigodo, y el Imperio Bizantino. Un ejemplo excepcional, en tanto que muestra la fusión de elementos arquitectónicos y pictóricos bizantinos con otros latinos en el período de dominación visigoda. Una evidencia singular de transferencia que puede aclarar o complementar el conocimiento sobre la cultura de una época de transición entre el mundo romano y el medieval.

\section{Resultados}

El Plan Director de la Sede de Égara se ha convertido pieza clave para el desarrollo socioeconómico de la ciudad y ha contribuido sobremanera a su proyección internacional. Los efectos de la restauración del conjunto han revertido positivamente en la ciudad. Por un lado, ha supuesto un incremento de recursos y trabajo en la comunidad local, transformando su realidad simbólica. Tras la finalización de los trabajos de restauración (2010), durante el 2011 la Sede de Égara recibió unos 200 visitantes diarios, alcanzando una cifra por encima de las expectativas del Ayuntamiento de Terrassa. La rehabilitación de la Sede de Égara ha tenido un fuerte impacto sobre el turismo de la ciudad. En el año 2019 la ciudad fue distinguida con la marca "Ciudad con carácter", que otorga la Agencia Catalana de Turismo. Por otra parte, el conjunto ha recibido recientemente la distinción «Sello Biosphere Destination», un compromiso por la sostenibilidad que adapta al turismo 17 objetivos de desarrollo sostenible de la ONU.

Por otro lado, el Plan Director ha contribuido sobremanera en el desarrollo del sentido de orgullo y pertenencia de los ciudadanos, la identidad local y la comunicación intergeneracional. Tras la ejecución del Plan Director, la Seu d’Ègara se ha convertido en el centro neurálgico de la vida cultural de la ciudad. Las entidades culturales de Terrassa han convertido el monumento en un escenario habitual de diversos eventos: Día del Patrimonio del grupo casteller Minyons de Terrassa; Festival poético "Elixir"; Festival de la Orquestra de Cámara de Terrassa (OCT48). Se trata de iniciativas vinculadas con el patrimonio que, en lugar de anclar a las ciudades en su pasado, las transforma en un escenario precioso para el intercambio cultural y la visibilidad externa.

\section{Conclusiones}

El Plan Director de la Sede de Égara ha transformado la realidad sociocultural de la ciudad de Terrassa. Tras los trabajos de restauración y museización se ha convertido en un ejemplo privilegiado de la integración del Patrimonio en una ciudad. Un espacio privilegiado para fomentar el desarrollo de la educación, la cohesión social y el intercambio cultural.

Las actuaciones contempladas en el proyecto han permitido estudiar, preservar y potenciar el conocimiento del monumento. Además del prolongado proceso de excavaciones e investigaciones, en los últimos años se ha llevado a cabo una adecuación museística para hacer más comprensible la riqueza de las diferentes épocas, y se han desarrollado acciones de dinamización cultural con el objetivo de contribuir al desarrollo educativo y a la cohesión social de la ciudad a través del patrimonio.

\section{Referencias}

AAVV, Un projecte de desenvolupament cultural i integració urbana del conjunt monumental de les Esglésies de Terrassa. Museu de Terrassa, 24 de novembre de 1994, inédito.

AAVV, Pla Director del Conjunt Monumental de les Esglésies de Sant Pere de Terrassa. Museu de Terrassa, març del 1998, inédito. 
AAVV, Memòria del Pla Director del Conjunt Monumental de les Esglésies de Sant Pere de Terrassa. Museu de Terrassa, 2011, inédito.

Ainaud de Lasarte, J. (1976). Los templos visigótico-románicos de Tarrasa. Madrid: Editora Nacional.

ARCOR. 2002. Sant Miquel de Terrassa. Documentació de la restauració d'octubre 2001 a març 2002 i noves aportacions a la documentació de l'obra. Terrassa: Arcor. Taller. Estudi. Conservació i Restauració de Pintura.

Ferran, D. (2009). Ecclesiae egarenses. Les esglésies de Sant Pere de Terrassa. Barcelona: Lunwerg.

Ferran, D. (2015). Les pintures murals de l'absis de Sant Miquel. Anàlisi iconogràfica. Terme 30, 118-125.

Garcia Llinares, G., Moro, A., Tuset. F. (2009). La Seu Episcopal d'Égara. Arqueologia d'un conjunt cristià del segle IV al segle IX. Serie Documenta 8; Tarragona: Institut Català d'Arqueologia Clàssica.

Guardia, M. (1992). La pintura mural pre-romànica de les esglésies de Sant Pere de Terrassa. Noves propostes d'estudi. En Actes del I Simposi Internacional sobre les Esglésies de Sant Pere de Terrassa (20-22 de novembre de 1991). Terrassa: Centre d'Estudis Històrics-Arxiu Històric Comarcal, 153-160.

López, J., Gorostidi. D. (2015). Les inscripcions visigodes de l'absis de Sant Miquel. Terme 30, 101-109.

Mancho, C. (2012). La peinture murale de haut Moyen Âge en Catalogne (IX-X siècle). Turnhout: Brepols.

Mancho, C. (2018). La decorazione delle chiese di Sant Pere de Terrassa, esempio dell'uso politico di monumenti tardo-antichi nell'altomedioevo. Hortus Artium Medievalium 24, 152-161.

Martí i Bonet, J.M (1992). Els origens del Bisbat d'Égara. En Actes del I Simposi Internacional sobre les Esglésies de Sant Pere de Terrassa (20-22 de novembre de 1991). Terrassa: Centre d'Estudis Històrics-Arxiu Històric Comarcal, 61-71.

Puig i Cadafalch, J. (1931). Les peintures du VIe siècle de la cathédrale d'Egara. Comptes rendus des séances de l'Académie des Inscriptions \&Belles-Lettres 75, 154-162.

Puig i Cadafalch, J. (1932). Les pintures del segle VI de la catedral d'Egara (Terrassa). Butlletí dels Museus d'Art de Barcelona, vol. II, 97-105.

Puig i Cadafalch, J. (1948). Noves descobertes a la catedral d'Ègara. Barcelona: Institut d'Estudis Catalans.

Sánchez, C. (2019) Singing to Emmanuel: The Wall Paintings of Sant Miquel in Terrassa and the 6th Century Artistic Reception of Byzantium in the Western Mediterranean. Arts, 8, 128.

Tracer (2009). Memoria Final de Restauración de las Pinturas Murales del ábside de la Iglesia de Santa María de Terrassa (Barcelona). Madrid: Diputación Foral de Álava.

Vilaseca, Ll., Guasch. N. (2004). Diagnosi de materials de les pintures murals de la cúpula de l'església de Santa Maria de Terrassa. En R. Ranesi, L. Domedel, C. Armengol. Projecte de Restauració de les Pintures Murals de Santa Maria de Terrassa. 